\title{
Commuting by Customized Bus: A Comparative Analysis with Private Car and Conventional Public Transport in Two Cities
}

\author{
Tao Liu and Avishai (Avi) Ceder \\ The University of Auckland, Auckland, New Zealand \\ Romain Bologna and Benjamin Cabantous \\ Urban Engineering School, EIVP, Paris, France
}

\begin{abstract}
Commuting is a major component in the creation of traffic and travel problems. Thus, more attention should be given to its practice. Private car (PC) transport, the dominant mode of commuting in most of the world's major cities, creates traffic-related social problems such as traffic congestion, traffic fatalities and injuries, and adverse environmental impacts. This study proposes a novel commuting travel mode-a customized bus (CB) transit system that provides advanced, personalized, and flexible demand-interactive minibus service using Internet, telephone, and smartphone apps. The aim was to assess and compare the performance of $C B$ with $P C$ and with conventional public transport (PT) systems. A methodological analysis framework was constructed to quantify operational performance measures that enable the comparison of the different travel modes. This analysis framework was then applied to two citiesAuckland, New Zealand, and Paris, France - to assess the overall performance metrics of $P C, P T$, and $C B$, such as travel costs, travel time, and fuel consumption. This comparison sheds light on the differences between the travel modes, their viability, and their competitiveness. The results of the case study show that $P C$ is the fastest commuting mode, but the travel costs incurred by it are twice as much as for PT and $C B$ and involve higher fuel consumption. $C B$ also can provide a useful alternative for commuter trips in Auckland and Paris. For increased commuter trips, $C B$ proved to be more efficient than the PC and PT modes. Finally, the CB system tends to be more profitable in Auckland than in Paris.
\end{abstract}

Keywords: Commuting, customized bus, private car, public transport, travel mode. 


\section{Introduction}

Commuting is a widespread social activity that plays an important role in daily life and constitutes a considerable share of total household trip-making. Private car (PC) transport is still the dominant mode of commuting in most major cities around the world (AASHTO 2015; Statistics NZ 2009; Statistics NZ 2014), and rapid economic growth and employment have led to increased numbers of commuters. Combined with rapid urban sprawl, this results in an increased use of PC, which has led to various traffic-related social problems, including traffic congestion, traffic fatalities and injuries, and adverse environmental effects. However, it seems that continual expansion of road networks and traditional demand-management measures have not been effective historically in mitigating such adverse effects (Liu and Ceder 2015; Xu et al. 2015). As a result, the need for an efficient, reliable, and reasonably-priced public transport (PT) system has become increasingly pressing (Ceder 2007, 2016).

Conventional PT systems, especially those involving buses, use an old concept involving fixed routes, fixed stops, fixed terminals, fixed timetables, and fixed vehicle and driver scheduling. This traditional PT concept produces services that are not always appealing and do not necessarily attract commuters (Ceder 2007, 2016). In fact, commuting as a daily activity generates the lowest level of positive affect as well as a relatively high level of negative affect (Stutzer and Frey 2008). For most people, long-distance commuting is often the cause of many physical, financial, and mental problems, such as stress and out-of-pocket costs. Likewise, it has an effect on the work-family balance and increases the risk of divorce (Koslowsky et al. 1995; Stutzer and Frey 2008; Sandow 2011). To make commuting using PT a pleasant experience, an advanced, attractive PT system needs to be developed. As pointed out by Ceder $(2007,2016)$, an advanced and attractive PT system should operate reliably and relatively rapidly, with smooth, synchronized transfers, as part of the door-to-door passenger chain.

Accordingly, customized bus (CB) offers such an attractive PT commuting system that provides advanced, personalized, and flexible demand-interactive PT service to commuters (Liu and Ceder 2015). It has been launched and implemented successfully in many cities around the world, such as Beijing, Lisbon, and San Francisco (Shaheen 2001; Eiró et al. 2011; Martínez et al. 2014; Liu and Ceder 2015), and has great potential for meeting the ever-increasing, diversified commuting mobility needs of large populations and helping to improve the commuting experience.

\section{Background on Customized Bus}

$\mathrm{CB}$ is a new and innovative mode of cyber-enabled, demand-interactive transit systems that provides advanced, attractive, and user-oriented minibus service to commuters by aggregating their similar travel-demand patterns using online information platforms such as Internet, telephone, and smartphone apps. Unlike conventional PT service, CB users are actively involved in various interactive operational planning activities, including online demand collection, network route design, timetable development, and vehicle and crew scheduling. CB service is more comfortable, convenient, and reliable than conventional PT service and more efficient, cost-effective, and environmentally-friendly than PC. Therefore, CB serves as a good alternative for reducing urban traffic congestion, 
improving traffic safety, and alleviating energy consumption and greenhouse gas emission problems (Eiró et al. 2011; Martínez et al. 2014; Liu and Ceder 2015).

$\mathrm{CB}$ can be regarded as a new hybrid transit system that integrates conventional fixedroute, fixed-schedule PT systems and demand-interactive collective transit systems such as carpooling, carsharing, and subscription bus (Shaheen 1998; TCRP 1999; Shaheen 2001). CB service is designed and implemented by using a human-computer interactive, integrated ridematching platform with the participation of users and operators. By interacting with users in real time, it closely caters to their demands and better meets ever-increasing, diversified, commuting mobility needs. Therefore, it is considered a viable and competitive alternative to private car and conventional PT service. A systematic description of the detailed operation-planning process of CB can be found in Liu and Ceder (2015).

\section{Objectives}

This study proposes a new commuting travel mode, a customized bus transit system, for commuters in Auckland, New Zealand, and Paris, France. The aim was to assess and compare the performance of this new transit system with PC and conventional PT systems. This work had three objectives: 1) to construct an initial methodological framework for quantifying operational performance measures, such as travel time, travel cost, energy consumption, 2) to apply this framework to assessing the overall performance of PC, PT, and CB in case studies in Auckland and Paris, and 3) to conduct comparisons between the cities and provide recommendations for actual $\mathrm{CB}$ service improvement and implementation.

\section{Related Literature Review}

\section{Commuting Mode Choice between Private Car and Public Transportation}

The choice of mode between PC and PT is a complex decision process that is influenced by various factors. Trip characteristics such as trip purposes, time, regularity, and household characteristics have been shown to be significant factors in mode choice (Ye et al. 2007). PC usually is perceived to be more attractive than PT because of its convenience, flexibility, independence, comfort, speed, and reliability and because driving is perceived to be more pleasurable and bears a status symbol (Steg 2003). The use of PT has been shown to decline as age and income increase. Women have a slightly higher probability of using PT for trip purposes other than commuting (Kuhnimhof et al. 2006). Other factors that have been identified are quality of PT services, lack of connection, out-of-pocket travel cost, access distance to and from stations, and distance to/from home-work (Galdames et al. 2001; Kingham et al. 2001). Terloolen et al. (1998) showed that PC travelers display a psychological resistance towards switching to PT.

PC use has been preferred to PT not only for its instrumental functions (freedom, comfort, and convenience), but also for its symbolic (status in society) and affective (driving is perceived as being pleasurable) functions (Hiscock et al. 2002; Beirão and Cabral 2007). Other literature has shown that once private vehicles are acquired, their use becomes more of a necessity than a luxury to the owner. Private vehicle use can become a habit for a large group of travelers after acquisition (Anable 2005). Increased 
complexity of trip chains due to changes in traditional household travel patterns with more women entering the workforce also has been identified as a barrier to PT use (Hensher and Reyes 2000; Nobis and Lenz 2005). Therefore, methods to instigate mode switch from PC to PT, particularly for commuters, remain a hot topic of interest for many transportation specialists.

\section{Commuter-based Carsharing}

The concept of vehicle sharing is not new. The earliest car-sharing system was introduced in Zurich in 1948 (Shaheen et al. 1998). There have been five phases in the history of North American ridesharing, and it is estimated that there are now about 638 ridesharing services in the U.S. and Canada (Chan and Shaheen 2012). The share of driving alone continues to grow for total commuting, whereas the share for carpooling has declined continuously since 1980 in the U.S. (AASHTO 2015). In recent years, new ridesharing programs that incorporate Internet, smartphone apps, and social networking have been developed for better online matching between commuters and service providers by employing information and communication technologies (Eiró et al. 2011; Chan and Shaheen 2012; Martínez et al. 2014; Liu and Ceder 2015). This new kind of travel mode is viewed as a good alternative to PC and a complementary mobility option that supports traditional PT systems.

\section{Methodological Framework}

The methodological framework for the comparative analysis of commuting travel modes is shown in Figure 1. This methodological framework was constructed by an input-component output format, elaborating the systematic decision sequence and process of the analysis. The output of each component positioned higher in the sequence becomes an important input into lower-level decisions. This analysis framework was customized to achieve the three objectives of this study. Accordingly, to determine and compare the performance measures for the three different commuting modes in Auckland and Paris, this customized framework included four stages:

1. Preliminary study area map establishment

2. Data collection

3. Determination of performance metrics

4. Performance comparison of travel modes

The first stage identified the study areas and established a preliminary road network map and PT networks. Potential commuting trips in the selected study areas were identified in the second stage. Data on trip origins/destinations, expected arrival times at destinations, and vehicle type used were collected. The demand collection process was completed by using a human-computer interactive with an integrated information platform such as Internet, telephone, and smartphone app with the participation of both users and operators. In this stage, grouping and vehicle routing strategies was adopted for designing and routing $\mathrm{CB}$ vehicles to pick up commuters from their origins and drop them off at their destinations. After generating the routes, Google Maps and Via Michelin Itinéraire smartphone app were used to collect data on trip travel time, travel cost, and fuel consumptions based on some simplified assumptions. In the last 
stage, performance comparisons of $\mathrm{PC}, \mathrm{PT}$, and $\mathrm{CB}$, and performance comparisons between Auckland and Paris were conducted using the calculated performance metrics.

FGURE 1.

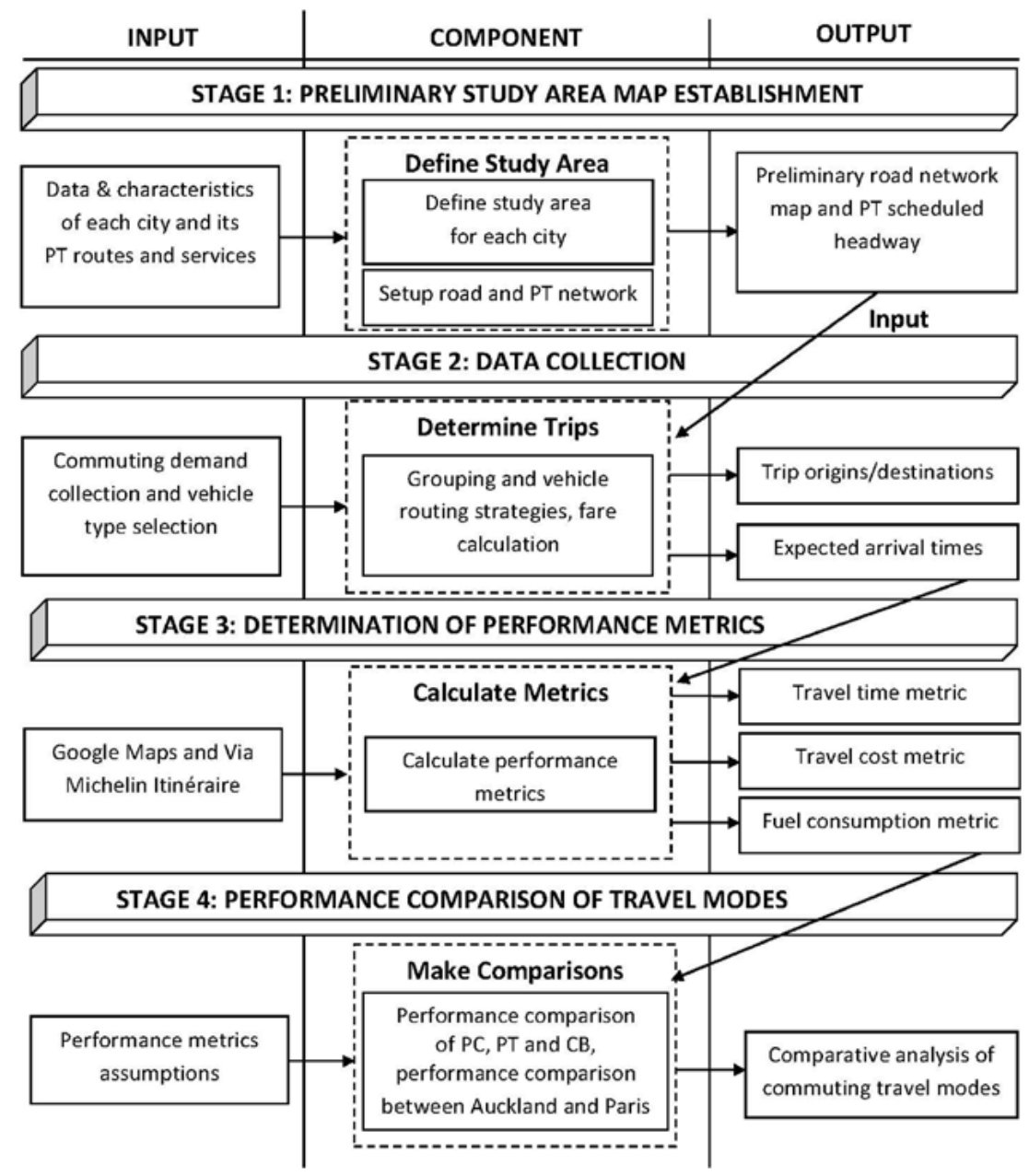

Overall, the performance metric comparisons of different commuting modes in different cities can help us to better understand the different travel modes and their viability and competitiveness in different conditions. This can help in planning for future $\mathrm{CB}$ improvements.

\section{Study Area}

\section{Auckland}

The Auckland metropolis is New Zealand's largest and most cosmopolitan region, with a population of 1.5 million. The Auckland region is a major part of the New Zealand's demography and economy, with a 35\% share of the national GDP (Statistics NZ 2013). Such a significant place obviously plays a leading role in the country's economy. It is a PC-dominated city and has serious traffic congestion during peak hours. It is estimated that more than 60 million trips are made annually within the Auckland metropolis by using PT systems, which consist of trains, buses, and ferries. For this study, only travel between Auckland suburbs and the central business district (CBD) that are daily work trips were considered. 
Figure 2 shows the study area, which includes the Auckland city center and the regions of Newmarket, Grey Lynn, Epsom, Penrose, Remuera, Ellerslie and Mount Wellington. All possible buses and three train lines in this area, namely the Southern line, the Eastern line and the Western line, were taken into consideration.
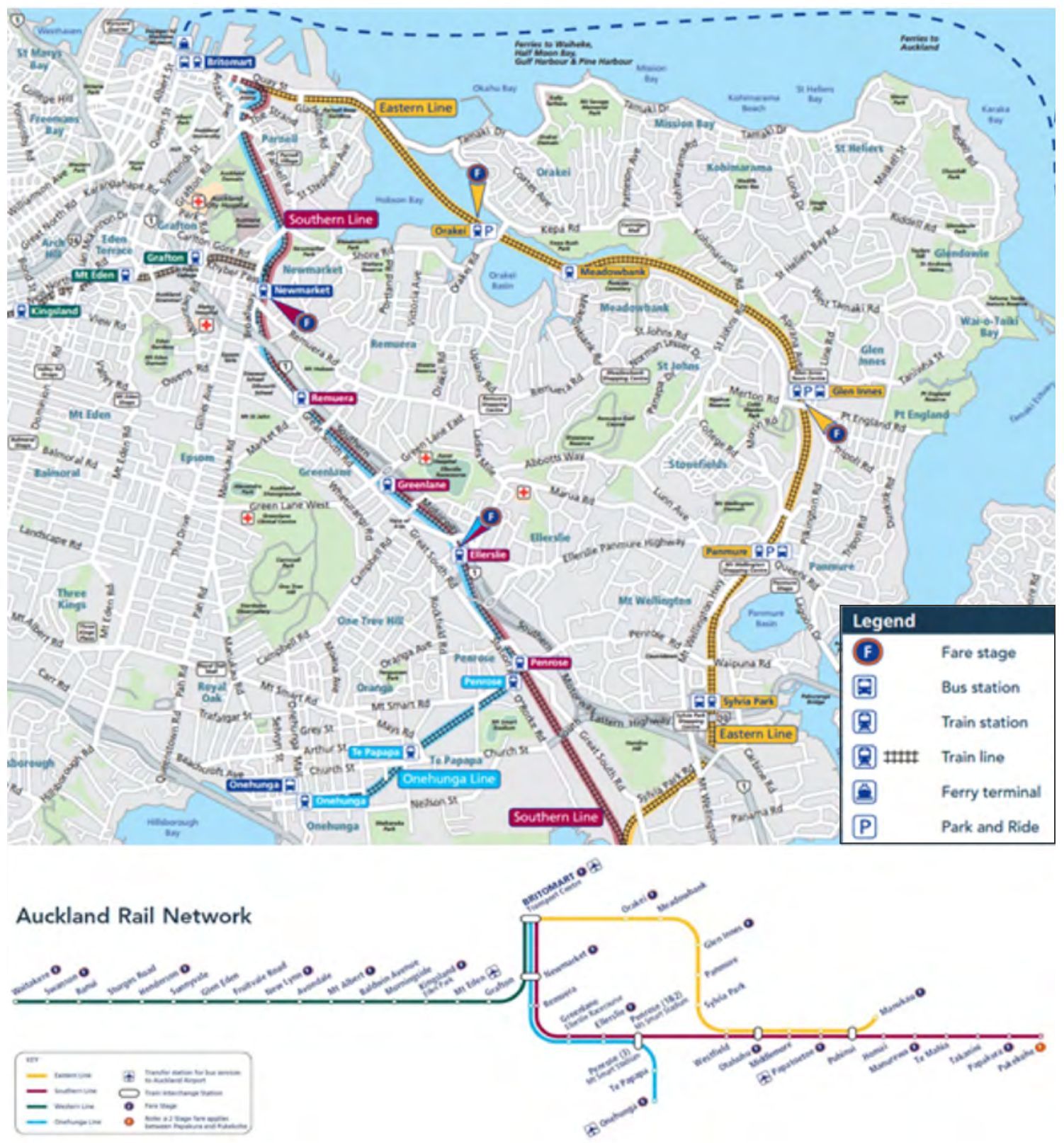

FIGURE 2. Study area in Auckland, New Zealand

\section{Paris}

The Paris metropolis is France's largest and most cosmopolitan region, with a population of 11.9 million and a GDP of 572,398 million euros (Institute Development and Urban Planning in the Region of île-de-France 2015). It is France's most productive (economically 
and socially) region. This economic activity would not be possible without an efficient commuter transport system, especially efficient PT systems. The RATP Group is the PT operator and provides a complex PT network that consists of trains, buses, metros, and tramways. It is estimated that there are three billion PT trips annually.

For this study, the selected area, as shown in Figure 3, included La Défense and the western part of metropolitan Paris, which is composed of the cities of Vauréal, Ménucourt, Courdimanche, Croissy, Aigremont, Carrières sous Poissy, Chambourcy, Fourqueux, MareilMarly, Bezon, and Houilles. Most of the people living in these cities work in Paris and have to travel long distances to and from work, either by private car or PT.

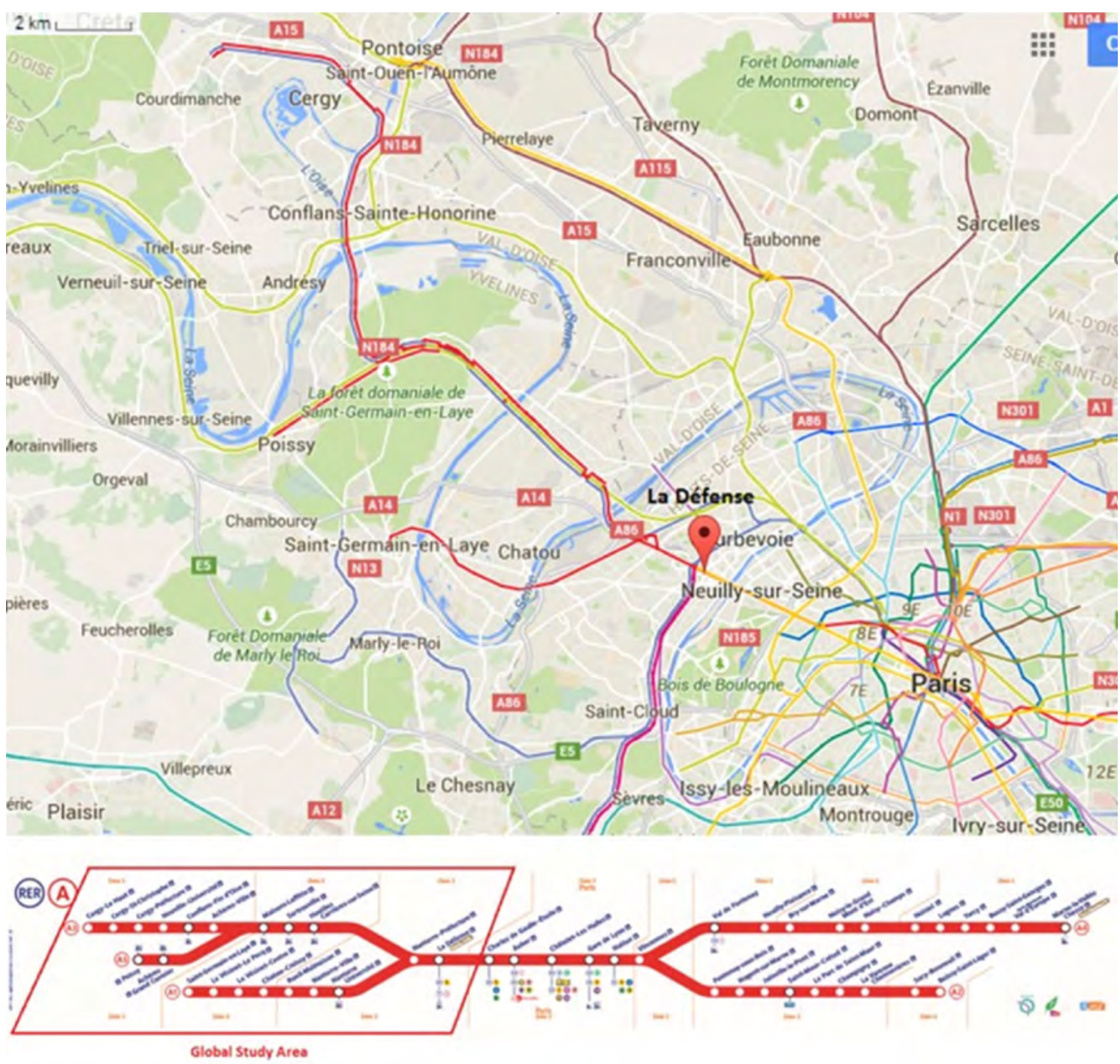

FIGURE 3. Study area in Paris, France

\section{Data Collection}

To compare the performances of the three different commuting modes-PC, conventional $\mathrm{PT}$, and $\mathrm{CB}$ - four performance metrics were determined: average 
difference between expected and actual arrival times, average total travel time, average total travel cost, and average total fuel consumption. The selected study time periods for the two study areas were from 6:45 AM to 10:00 AM, spread over normal and rush hours to obtain a global view of different traffic conditions.

For the two study areas, trip origins in which commuters can use both PC and PT were regarded as potential service points. For the purposes of a representative sample, 100 trips in Paris and 100 trips in Auckland were examined. For Paris, five different RER A train stations and 20 addresses in the proximity of each station were selected in the attempt to cover as large an area as possible. Google Maps was used to do this work, as illustrated in Figure 4(a).

FIGURE 4.

Using Google Maps and Via Michelin Itinéraire to collect data

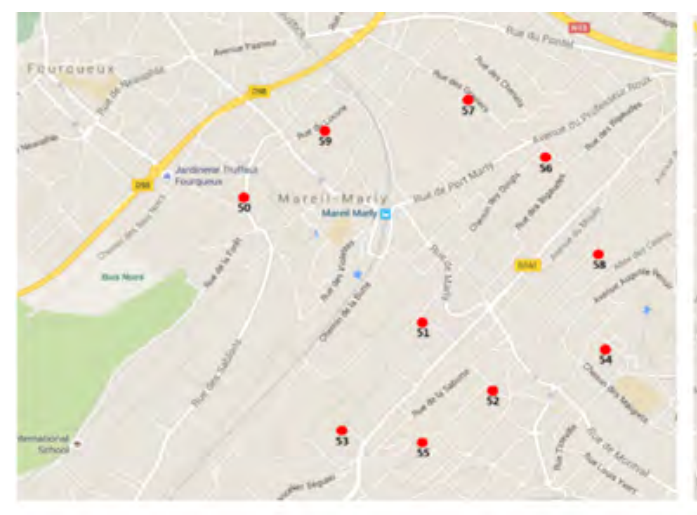

(a) Candidate trip origins selection

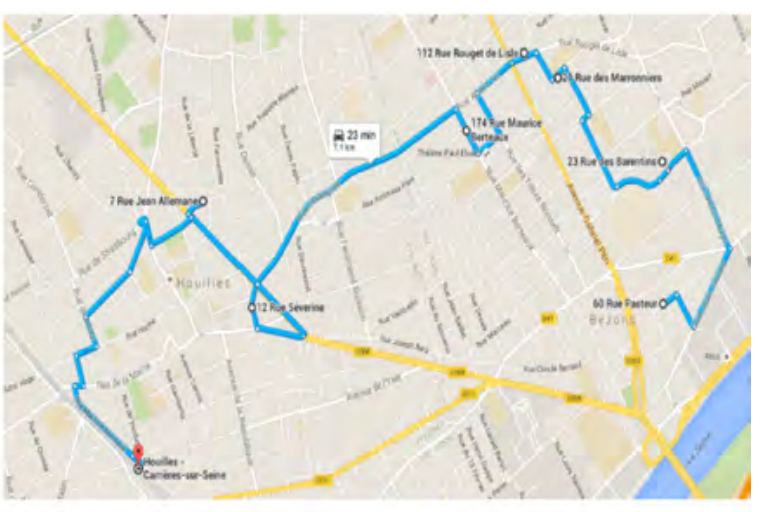

(b) Travel time estimation

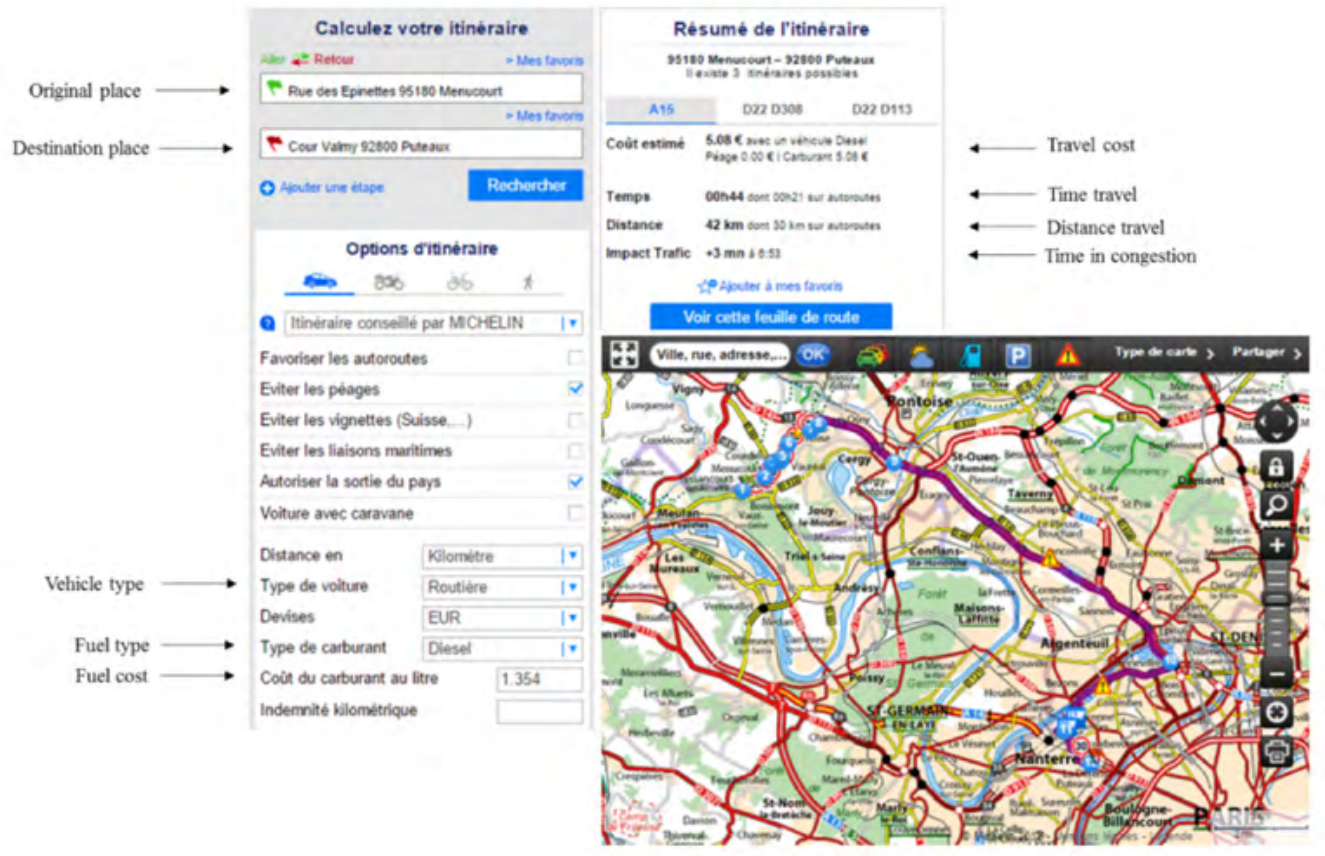

(c) User interface of Via Michelin app 
The Via Michelin app was used to collect PC data. As shown in Figure 4(c), the app allows the user to choose between distance and money device, vehicle, and fuel type. Fuel cost can be adjusted by the user. Thereafter, the user needs only to enter the original and destination places. The app calculates the best way and gives the travel cost in euros, travel time, time to be spent in congestion, and distance to be traveled. To collect PT data, bus and RER timetables were used, and those that included the lowest transfer waiting time were selected.

In addition, the shortest travel paths were selected to collect CB data. First, a grouping strategy was used to group potential commuters into common trips by a minibus with 15 seats. The first selection feature was the RER timetable. People were grouped with similar origins/destinations into the same CB trip. To be profitable, minibuses should travel with at least six passengers. When this loading level is not met, $C B$ service is not provided. In this case, groups were changed, forcing people to take a train; sometimes, individual trips were not grouped into common trips due to the long difference between expected arrival time and actual arrival time. In this case, travelers involved had to use PC or PT. After grouping, the nearest neighbor algorithm (Haksever et al. 2000) was used to determine the routing of minibuses. After determining the routes, Google Maps was used to estimate the entire travel time needed for each route. Figure 4 (b) shows an example of estimating route travel time in Paris.

\section{Data Processing \\ Difference Arrival Time}

The expected arrival time (EAT) is the time at which a commuter hopes to arrive at his/ her destination. The difference arrival time (DAT) is the difference between the EAT and the actual arrival time (AAT). For conventional PT, AAT depends on planned timetables and road traffic conditions. To determinate DAT, EAT was fixed for each passenger.

Google Maps and Via Michelin Itinéraire (for Paris) were used to get the time and route of travel trips for PC commuters. In same way, by combining the timetables of buses and trains, the AAT of each commuter using conventional PT also could be obtained. DAT was calculated by

$$
D A T=|E A T-A A T|
$$

\section{Travel Time (TT)}

The total travel time (TTT) may contain several parts, such as in-vehicle travel time, outof-vehicle waiting time, walking time, and transfer waiting time. For PC, the TTT is the sum of the time spent driving from home to the car parking place (TT) and the walking time from the parking place to the workplace (WkT). Both were estimated with Google Maps. The estimation was run from 7:00 AM to 10:00 AM based on the departure hour of each passenger. An estimation of the time lost in congestion also was included in the final results.

Using the same methods, the estimation for PT was repeated. Here, TT denotes the time spent on buses or trains. The WkT is composed of the walking time to the bus/ train stations, the potential walking time for making transfers, and the walking time to the workplace. However, in the case of including transfers, some extra time may be 
wasted because of transfer waiting; this transfer waiting time is denoted by WtT. Using Google Maps to determine an itinerary, routes were specified in detail. The transfer waiting time was then calculated by simple subtraction.

The travel data with the $\mathrm{CB}$ were separated into two parts. First, commuters are picked up by minibuses, and then brought to the nearest train stations. The nearest neighbor algorithm was adopted to generate vehicle routes based on a predefined loading level. The estimation of TTT for CB based on the summation of all individual origin to destination pairs was the same as that done for PT. It should be noted that for $\mathrm{CB}$, the TT is composed of the time spent in the minibus and the train, and the WkT corresponds to the travel time from the final train station to the workplace. Thus, the TTT for CB was calculated by

$$
T T T=T T+W k T=W t T
$$

\section{Travel Cost}

For most people, travel cost (TC) is one of the dominant factors in their choice of commuting travel modes (Chowdhury et al. 2015). Travel costs were calculated for the whole day, taking both morning and evening trips into consideration.

Diesel is the fuel used most in New Zealand and France. Accordingly, our hypothesis relates to calculations for vehicles operating on diesel engines. In France, the diesel price is $€ 1.354 / L$ (MoEID 2015). The Via Michelin app was used to get the fuel consumption (FC) in euros for one-way trips. Then, the car parking price (CPP) per day was calculated.

For Auckland, a price of $\$ 1.33 / \mathrm{L}$ was used (AA 2015), and distance traveled was estimated using Google Maps. The FC was determined by multiplying the distance and unit distance price. For this study, the daily car parking price had to be estimated due to a lack of accurate information regarding monthly subscription rates; the calculation was made by

$$
T C=(2 \mathrm{x} F)+\mathrm{CPP}
$$

In Paris, a subscription card called Navigo Card allows the use of buses tramways, metros, and the Paris RER for one year with the card. The subscription price (SP) depends on the areas in which the travel takes place. The Paris metropolis is divided into five tariff zones, as shown in Figure 5. This study related only to a subscription for areas 3-4 and 3-5, which have an SP of $€ 2.06 /$ day and $€ 2.5 /$ day, respectively. 


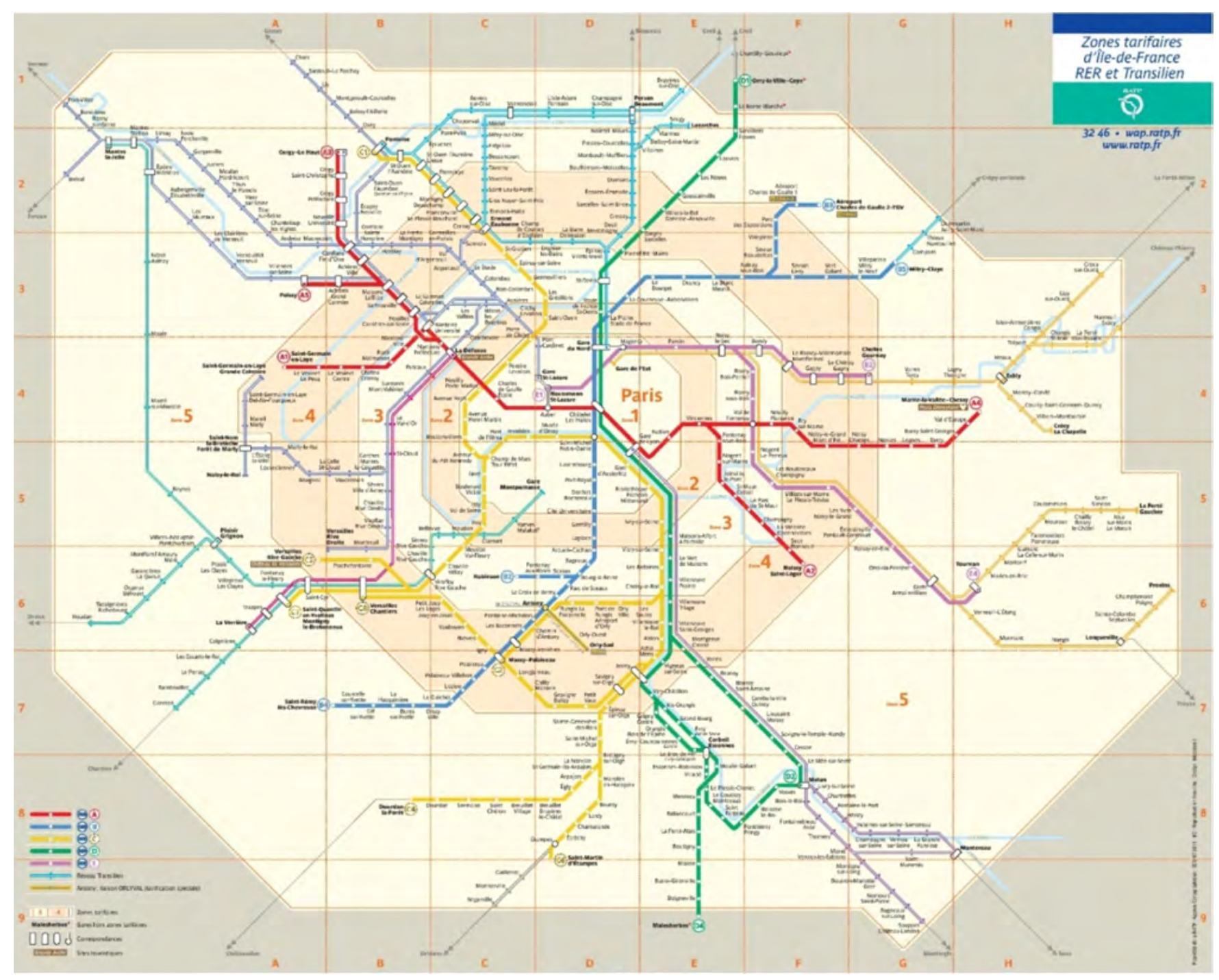

FIGURE 5. Paris tariff zones

To estimate $\mathrm{CB}$ cost, the following distance tariff scheme was used, which includes two fare components: variable fare and constant fare. The variable fare was calculated by

$$
F_{1}=\max \left\{0, F^{\prime} \cdot\left\lceil\frac{L-L_{0}}{L_{1}}\right]\right\}+F_{0}
$$

where $L$ is the length of a trip, $F_{0}$ is the basic fare that is compulsorily charged as long as one uses the $\mathrm{CB}$ service, $F^{\prime}$ is the fare factor employed for calculating fares for different trip lengths, $L_{0}$ and $L_{1}$ are the threshold length and length factor respectively, and function $\lceil x\rceil$ is the celling function, which gives the smallest integer 
$\geq x$. According to this definition, when the length of a trip is less than the threshold length, $L_{0}$, the charge will be only for the basic fare $F_{0}$.

Combining the variable fare with the constant fare, the total fare was calculated by

$$
F=\alpha_{1} \cdot F_{1}+\alpha_{2} \cdot F_{2}
$$

where $F_{2}$ is the constant fare, $\alpha_{1},\left(0 \leq \alpha_{1} \leq 1\right)$ and $\alpha_{2},\left(0 \leq \alpha_{2} \leq 1\right)$ are the discount factors of the constant fare and the variable fare, respectively.

The cost per kilometer includes fuel cost, maintenance cost, driver payment, and insurance. A fuel consumption of $26 \mathrm{~L} / \mathrm{km}$ at a price of $€ 1.354 / \mathrm{L}$ was considered, which amounts to a fuel cost of $€ 0.352 / \mathrm{km}$. For the maintenance cost, an Iveco minibus was used as an example, which has a maintenance cost of $€ 0.0229 / \mathrm{km}$. In France, the average driver income is around $€ 1550$ per month (CIDJ 2015). As minibus maintenance is necessary either every six months or every $10,000 \mathrm{~km}$, it was considered that a driver travels around $1667 \mathrm{~km}$ in one month. In keeping with these estimations, the driver wage was estimated to be $€ 0.93 / \mathrm{km}$. Insurance costs are around $€ 4000$ per year. Using the same hypothesis as above, the insurance cost was $€ 0.2 / \mathrm{km}$. Thus, the outcome is $F_{0}$ $=€ 1.29$. We set $L_{0}=5.16 \mathrm{~km}, L_{1}=10$, and $F^{\prime}=2$, which are the common values used in practice. Repeating the same process, $F_{0}=\$ 2.75$ and $L_{0}=6.57 \mathrm{~km}$ for Auckland. Subsequently, Eq. (5) was used to calculate the travel cost for CB users.

\section{Fuel Consumption}

Fuel consumption (FC) was calculated by liter per person. For cars in Paris, the Via Michelin app was used to obtain the FC in euro per person, which was divided by the diesel price of $€ 1.354 / \mathrm{L}$. For Auckland, an average fuel consumption of $8.61 \mathrm{~L} / 100 \mathrm{~km}$ was used and was multiplied by the distance traveled (D). For PT, fuel consumption was estimated to be $0.45 \mathrm{~L} / \mathrm{km}$, which was multiplied by the distance traveled (D) and then divided by the number of people on the bus, estimated at an average of 10 people. The FC for PT was calculated by

$$
F C_{p t}=\frac{0.45 \times D}{10}
$$

The fuel consumption of $C B$ was estimated to be $0.26 \mathrm{~L} / \mathrm{km}$, which is the average consumption of a minibus. The calculation method was the same as for PT, but minibuses with 15 seats were considered, with an average of seven on-board users assumed. Thus, the FC for PT was calculated by

$$
F C_{c b}=\frac{0.26 \times D}{7}
$$




\section{Results}

For each study area, 100 candidate commuting trips were randomly generated. Travel time, travel cost, and fuel consumption data were collected for all trips. Average values were calculated to make comparisons of the three different commuting travel modes.

\section{Auckland}

The group-specific results obtained for the Auckland case study are summarized in Table 1. This table includes the performance metrics of the difference arrival time ( $\mathrm{min}$ ), walking time from parking place to workplace $(\mathrm{min})$, transfer waiting time ( $\mathrm{min})$, total travel time ( $\mathrm{min})$, travel cost $(€ /$ day), and fuel consumption (L/person).

TABLE 1.

Performance Metrics Measured per Group in Auckland

\begin{tabular}{|c|c|c|c|c|c|c|c|c|c|c|}
\hline & Group & 1 & 2 & 3 & 4 & 5 & 6 & 7 & 8 & Average \\
\hline \multirow{3}{*}{$\begin{array}{l}\text { DAT } \\
(\mathrm{min})\end{array}$} & PC & 0 & 0 & 0 & 0 & 0 & 0 & 0 & 0 & 0 \\
\hline & $C B$ & 4.63 & 4.43 & 3.43 & 7.71 & 2.17 & 4.29 & 6.43 & 2.49 & 4.45 \\
\hline & PT & 5.38 & 5.57 & 4.86 & 3.43 & 3.50 & 4.86 & 3.43 & 4.98 & 4.50 \\
\hline \multirow{3}{*}{$\begin{array}{l}\mathbf{W} \mathbf{k} \mathbf{T} \\
(\min )\end{array}$} & PC & 3.63 & 3.86 & 4.14 & 4.14 & 4.17 & 4.57 & 4.00 & 4.08 & 4.07 \\
\hline & CB & 9.38 & 9.57 & 5.71 & 5.57 & 4.33 & 6.14 & 8.43 & 8.84 & 7.25 \\
\hline & PT & 14.00 & 11.29 & 10.43 & 9.57 & 10.50 & 9.57 & 10.00 & 13.59 & 11.12 \\
\hline \multirow{3}{*}{$\begin{array}{l}\mathbf{W t T} \\
(\mathrm{min})\end{array}$} & $P C$ & 0 & 0 & 0 & 0 & 0 & 0 & 0 & 0 & 0 \\
\hline & $\mathrm{CB}$ & 0 & 0 & 0 & 0 & 0 & 0 & 0 & 1.56 & 0 \\
\hline & PT & 4.75 & 5.71 & 3.71 & 0.00 & 7.33 & 5.57 & 0.86 & 3.12 & 3.88 \\
\hline \multirow{3}{*}{$\begin{array}{l}\text { TTT } \\
(\min )\end{array}$} & PC & 37.13 & 38.57 & 33.57 & 25.43 & 33.33 & 35.00 & 22.43 & 34.41 & 32.48 \\
\hline & $C B$ & 45.25 & 43.29 & 41.29 & 39.43 & 39.67 & 40.00 & 45.29 & 38.83 & 41.63 \\
\hline & PT & 50.38 & 51.29 & 45.14 & 38.71 & 46.00 & 45.43 & 35.43 & 43.24 & 44.45 \\
\hline \multirow{3}{*}{$\begin{array}{l}\text { TC } \\
\text { (NZ\$/day) }\end{array}$} & PC & 16.39 & 16.25 & 15.85 & 13.21 & 15.98 & 15.89 & 13.17 & 15.68 & 15.30 \\
\hline & $C B$ & 6.35 & 6.21 & 6.10 & 5.53 & 5.93 & 6.13 & 5.63 & 11.46 & 6.67 \\
\hline & PT & 8.78 & 9.37 & 9.29 & 3.77 & 9.50 & 8.60 & 5.00 & 7.25 & 7.69 \\
\hline \multirow{3}{*}{$\begin{array}{l}\text { FC } \\
\text { (L/person) }\end{array}$} & PC & 2.14 & 2.08 & 1.93 & 0.95 & 1.98 & 1.95 & 0.93 & 1.71 & 1.71 \\
\hline & $\mathrm{CB}$ & 1.01 & 1.04 & 1.08 & 0.57 & 0.98 & 1.08 & 0.66 & 1.26 & 0.96 \\
\hline & PT & 1.00 & 0.99 & 0.92 & 0.44 & 0.95 & 0.92 & 0.44 & 0.81 & 0.81 \\
\hline
\end{tabular}

$D A T=$ difference arrival time, $W k T=$ walking time from parking place to workplace, $W t T=$ transfer waiting time, $T T T=$ total travel time, $T C=$ travel cost, $F C=$ fuel consumption, $P C=$ private car, $C B=$ customized bus, $P T=$ public transportation

The average results for these eight groups are graphically shown in Figure 6. It can be seen that, generally, in Auckland, PT and CB perform somewhat similarly compared to PC. However, CB appears to be less expensive than both PT and PC. This may be because PT service in Auckland is very expensive. What's more, $\mathrm{PC}$ has the shortest average travel time and lowest average difference time; however, it consumes much more fuel and costs much more than PT and CB. Although CB consumes a little more fuel than conventional PT, it provides much greater comfort, as it eliminates congestion and transfer waiting and guarantees seats. More importantly, this initial study was limited by the number of candidate trips. If more commuter trips are taken into account, the CB will be more efficient than PC and PT. 
FIGURE 6.

Average

performance

metrics

measured

per mode in

Auckland
Average DifferenceArrival Time (min)
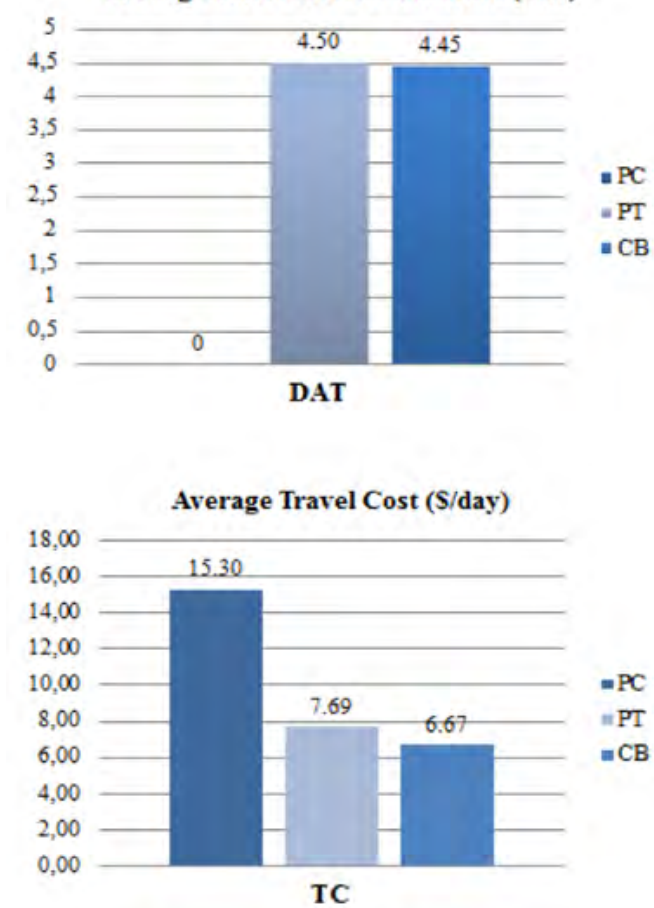

Average Total Travel Time (min)
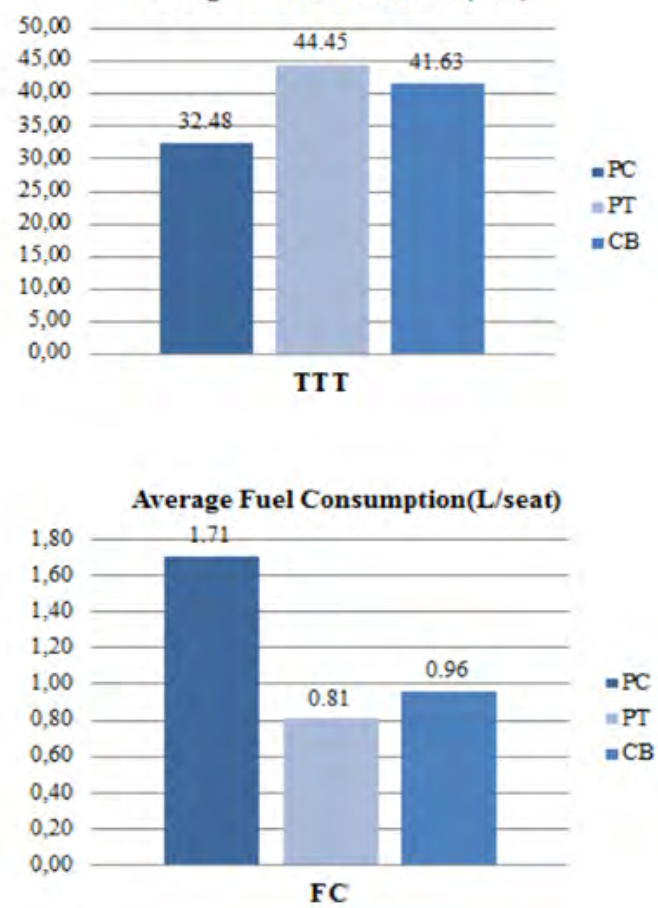

Paris

Table 2 shows group-specific results obtained from the Paris case study. It should be noted that the $12^{\text {th }}$ group is composed of 25 commuting trips that could not be grouped due to low vehicle loading levels. The average metric values for all groups were calculated to compare the performance of the different three travel modes; the average results of these 12 groups are shown in Figure 7, which illustrates that PC has the lowest deviation from expected arrival time and $\mathrm{CB}$ has the largest deviation from expected arrival time. This may reflect the small and poor sample trips that were distributed over a relatively large area, which increases the time for picking up commuters from their homes. However, compared to $\mathrm{PC}, \mathrm{CB}$ is much cheaper and consumes much less fuel. Moreover, a comparison between CB and PT shows that CB is $15 \%$ faster than PT, but is $33 \%$ more expensive than PT. This may be a result of the reduced transfer time. The average travel cost and fuel consumption could be further reduced for $\mathrm{CB}$ by involving more commuting trips. 
TABLE 2. Performance Metrics Measured per Group in Paris

\begin{tabular}{|c|c|c|c|c|c|c|c|c|c|c|c|c|c|c|}
\hline & Group & 1 & 2 & 3 & 4 & 5 & 6 & 7 & 8 & 9 & 10 & 11 & 12 & Average \\
\hline \multirow{3}{*}{$\begin{array}{l}\text { DAT } \\
(\min )\end{array}$} & PC & 0 & 0 & 0 & 0 & 0 & 0 & 0 & 0 & 0 & 0 & 0 & 0 & 0 \\
\hline & $\mathrm{CB}$ & 13.14 & 14.50 & 29.50 & 17.22 & 20.00 & 19.13 & 22.29 & 23.00 & 18.17 & 22.29 & 21.67 & 10.42 & 19.28 \\
\hline & PT & 6.86 & 7.50 & 7.50 & 22.33 & 9.33 & 6.88 & 9.71 & 3.57 & 18.00 & 5.86 & 25.17 & 20.84 & 11.96 \\
\hline \multirow{3}{*}{$\begin{array}{l}\mathbf{W} \mathbf{k} \mathbf{T} \\
(\mathrm{min})\end{array}$} & PC & 5.00 & 5.00 & 4.67 & 5.00 & 4.33 & 5.00 & 5.00 & 5.29 & 4.67 & 4.71 & 5.67 & 5.08 & 4.95 \\
\hline & $C B$ & 10.57 & 8.83 & 10.00 & 12.11 & 7.50 & 11.13 & 9.29 & 12.71 & 10.17 & 8.00 & 10.17 & 11.30 & 10.15 \\
\hline & PT & 15.86 & 13.67 & 20.33 & 21.89 & 15.17 & 18.00 & 13.00 & 15.14 & 14.33 & 17.14 & 20.33 & 17.52 & 15.41 \\
\hline \multirow{3}{*}{$\begin{array}{l}\mathbf{W t T} \\
(\min )\end{array}$} & PC & 0 & 0 & 0 & 0 & 0 & 0 & 0 & 0 & 0 & 0 & 0 & 0 & 0 \\
\hline & $\mathrm{CB}$ & 0 & 0 & 0 & 0 & 0 & 0 & 0 & 0 & 0 & 0 & 0 & 0 & 0 \\
\hline & PT & 6.29 & 3.50 & 14.00 & 6.00 & 4.67 & 6.88 & 7.57 & 4.71 & 6.00 & 6.29 & 6.29 & 6.56 & 6.25 \\
\hline \multirow{3}{*}{$\begin{array}{l}\text { TTT } \\
(\min )\end{array}$} & PC & 63.00 & 55.33 & 50.83 & 41.67 & 43.17 & 44.50 & 26.00 & 34.29 & 32.50 & 29.86 & 34.50 & 45.40 & 41.75 \\
\hline & $C B$ & 65.00 & 65.33 & 52.33 & 50.56 & 47.67 & 50.13 & 38.86 & 43.14 & 37.00 & 36.57 & 34.33 & 52.32 & 47.77 \\
\hline & PT & 70.71 & 63.33 & 72.33 & 64.33 & 57.50 & 62.75 & 42.57 & 42.57 & 40.50 & 56.00 & 48.33 & 59.24 & 56.68 \\
\hline \multirow{3}{*}{$\begin{array}{l}\text { TC } \\
(€ / \text { day })\end{array}$} & PC & 14.69 & 14.55 & 12.26 & 11.09 & 11.74 & 10.94 & 8.55 & 9.48 & 8.66 & 7.49 & 7.99 & 12.09 & 10.79 \\
\hline & $C B$ & 3.15 & 3.18 & 2.92 & 3.29 & 3.21 & 3.42 & 2.63 & 2.71 & 2.58 & 2.74 & 2.58 & 7.20 & 3.30 \\
\hline & PT & 2.5 & 2.5 & 2.5 & 2.06 & 2.06 & 2.06 & 2.06 & 2.06 & 2.06 & 2.06 & 2.06 & 2.30 & 2.19 \\
\hline \multirow{3}{*}{$\begin{array}{l}\text { FC } \\
\text { (L/person) }\end{array}$} & PC & 3.65 & 3.48 & 2.63 & 2.06 & 2.20 & 2.11 & 1.29 & 1.37 & 1.30 & 0.89 & 1.05 & 2.37 & 2.03 \\
\hline & $\mathrm{CB}$ & 0.34 & 0.39 & 0.32 & 0.36 & 0.41 & 0.22 & 0.23 & 0.25 & 0.22 & 0.26 & 0.23 & 1.29 & 0.38 \\
\hline & PT & 0.16 & 0.12 & 0.17 & 0.28 & 0.28 & 0.28 & 0.10 & 0.11 & 0.22 & 0.26 & 0.23 & 1.29 & 0.19 \\
\hline
\end{tabular}

$D A T=$ difference arrival time, $W k T=$ walking time from parking place to workplace, $W t T=$ transfer waiting time, TTT = total travel time, $T C=$ travel cost,$F C=$ fuel consumption, $P C=$ private car,$C B=$ customized bus, $P T=$ public transportation

FIGURE 7.

Average

performance metrics measured per mode in Paris

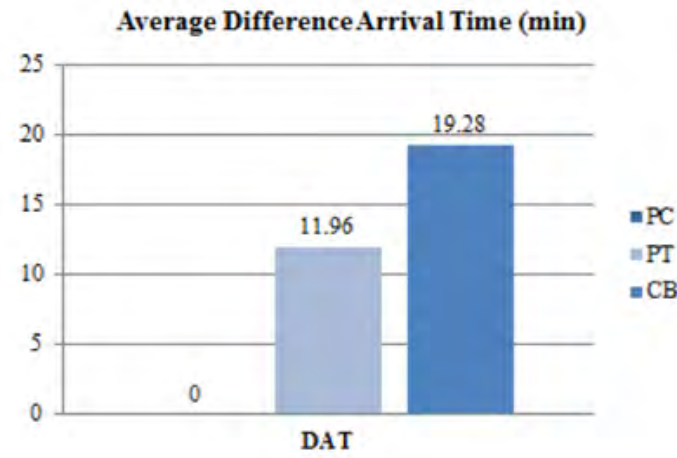

Average Travel Cost (\$/day)

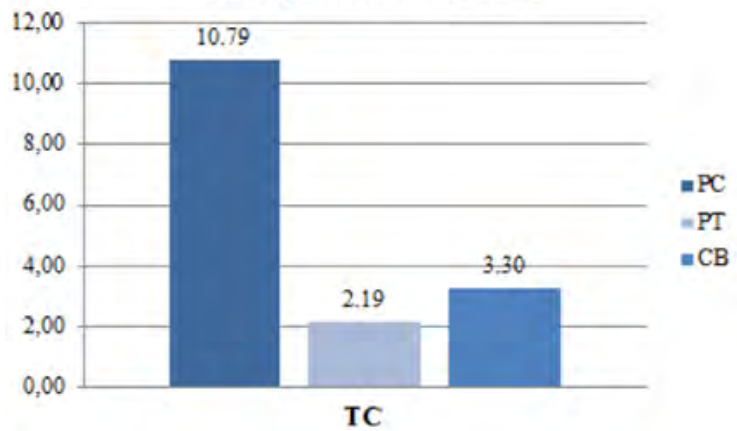

Average Total Travel Time (min)

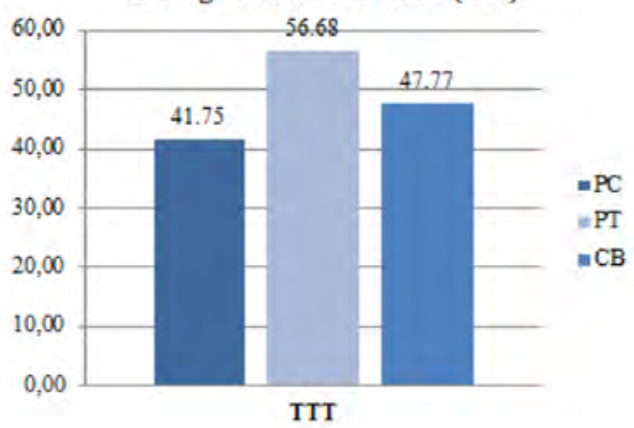

Average Fuel Consumption(L/seat)

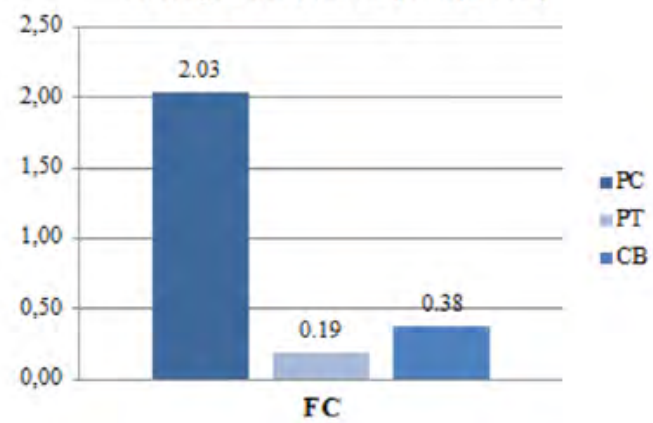




\section{Comparisons of the Two Cities}

From the case study results for Auckland and Paris, it has been shown that CB is a promising commuting mode compared to PC and conventional PT. In both cities, compared to PC, CB has a lower average travel cost and consumes much less fuel. However, it appears that it is more suitable and performs much better in Auckland than in Paris. Indeed, in terms of average travel cost, PT is more attractive than CB in Paris, whereas the opposite result was attained for Auckland. In addition, the PT network in Paris is better than that in Auckland because of better PT network connectivity (mainly because of its Metro service), transfer synchronization, and service frequencies. Moreover, in Paris, the DAT of CB is twice that of PT, which could be of significant concern to commuters. However, this is a direct result of the manner of creating the groups for $C B$ and the limited size of the study sample. This is the main reason why $C B$ performs much better in Auckland.

Currently, there is a lack of investment in increasing the efficiency of Auckland PT systems, which inevitably would lead to mass use of PC. The Auckland Regional Public Transport Plan was created recently for the purpose of shifting public transport routing towards a hierarchical structure of networks that interact with each other so as to improve accessibility to PT service (Auckland Transport 2013). This study revealed that CB can be a good alternative to PC and PT and can help to improve commuter travel in Auckland. CB may help to reduce not only traffic congestion but also commuting travel costs. Furthermore, in Auckland, using PT or CB is basically similar with respect to price, travel time, and DAT. The only advantage for PT is fuel consumption, which is $15 \%$ less than $\mathrm{CB}$. However, $\mathrm{CB}$ brings comfort with the commuting experience, reducing walking, waiting, and transferring times.

If minibus consumption was lowered and an attractive price compared to PT was maintained, CB would appear to be a very attractive solution in Auckland. For Paris, both fuel consumption and travel costs of $C B$ are a little higher than those of PT, thus complicating its competitiveness with PT. However, if there are participants, $\mathrm{CB}$ can beat PC and PT.

\section{Conclusions}

With traffic congestion as a global issue in urban cities due to massive use of private vehicles by commuters, government agencies have focused on creating an attractive alternative. However, the conventional PT system possesses a high level of negative affect and requires improvements. The aim of this study was to propose a new commuting travel mode: customized buses. This potential novel transportation mode was compared to PT and PC in the cities of Auckland and Paris. Accordingly, a methodological framework was constructed to quantify operational performance measures. Subsequently, this framework was applied to the two cities to assess overall performance of PC, PT, and CB. Performance metrics such as travel cost, travel time, and fuel consumption were evaluated. Ultimately, a comparison of results for the each city was made reflecting improvements $C B$ could provide, followed by recommendations for actual implementation. 
The results show that the PC is the fastest and most reliable mode of commuting, as expected. However, travel cost by PC is twice as much as for PT or CB in both Paris and Auckland and also consumes considerably more fuel. The results also demonstrate that a CB system would be more profitable in Auckland than in Paris. The French capital's first class commuter transport system is better than CB with respect to most performance measures selected. Indeed, commuters would reduce not only their travel costs but also the difference in arrival time by using PT instead of CB. On the contrary, in Auckland, PT and CB exhibit many similarities. Both average DAT and average travel time are almost the same. However, using $C B$ in Auckland would be financially attractive due to a lower fare cost than PT. Regardless of the city, even though private car is still in the lead, by far, CB appears to consume more fuel than PT. This singular shortcoming is superseded by the comfort CB brings to commuters. Reducing walking time, less wasted time during transfers, and assuring uncrowded vehicles contribute to commuters feeling at ease.

In summary, this study revealed that $\mathrm{CB}$ can provide a useful alternative for commuting travel in Auckland and Paris. However, this initial study was limited by the number of candidate trips. If more commuter trips were considered, $\mathrm{CB}$ would prove to be more efficient than PC and PT. Generally speaking, a CB system can improve its performance in urban areas with long commuting distance, high population density, and inefficient existing PT systems. Further research can evaluate the impact using an electric minibus on the performance of $\mathrm{CB}$ systems as well as the impact of other factors such as accessibility, flexibility, and value of time on commuters' mode choice behavior.

\section{References}

AA. 2015. http://www.aa.co.nz.

American Association of State Highway and Transportation Officials (AASHTO). 2015. Commuting in America 2013: The National Report on Commuting Patterns and Trends. http://traveltrends.transportation.org/Pages/default.aspx.

Anable, J. 2005. "'Complacent Car Addicts' or 'Aspiring Environmentalists'? Identifying Travel Behaviour Segments Using Attitude Theory." Transport Policy, 12(1): 65-78.

Auckland Transport. 2013. Auckland Regional Public Transport Plan. https://at.govt.nz/media/308538/RPTP-2013-updateNov29-13.pdf.

Beirão, G., and J. S. Cabral. 2007. "Sarsfield-Cabral Understanding Attitudes towards Public Transport and Private Car: A Qualitative Study." Transport Policy, 14(6): 478489.

Ceder, A. 2007. Public Transit Planning and Operation: Theory, Modeling and Practice. Oxford, UK: Elsevier.

Ceder, A. 2016. Public Transit Planning and Operation: Modeling, Practice and Behavior, 2nd ed., Boca Raton: CRC Press.

Chan, N. D., and S. A. Shaheen. 2012. "Ridesharing in North America: Past, Present, and Future." Transport Reviews, 32(1): 93-112. 
Chowdhury, S., A. Ceder, and B. Schwalger. 2015. "The Effects of Travel Time and Cost Savings on Commuters' Decision to Travel on Public Transport Routes Involving Transfers." Journal of Transport Geography, 43: 151-159.

CIDJ. 2015. http://www.cidj.com/article-metier/conducteur-conductrice-d-autobus.

Eiró, T., L. Martínez, and J. Viegas. 2011. "Configuration of Innovative Minibus Service in the Lisbon, Portugal, Municipality: Spatial-Temporal Assessment." Transportation Research Record, 2217: 127-135.

Galdames, C., A. Tudela, and J. A. Carrasco. 2001. “Exploring the Role of Psychological Factors in Mode Choice Models by a Latent Variables Approach." Transportation Research Record, 2230: 68-74.

Haksever, C. B. Render, R. Russell, and R. Murdick, 2000. Service Management and Operations, 2nd ed. Upper Saddle River, NJ: Prentice Hall.

Hensher, D. A., and A. J. Reyes. 2000. "Trip Chaining as a Barrier to the Propensity to Use Public Transport." Transportation, 27(4): 341-361.

Hiscock, R., S. Macintyre, A. Kearns, and A. Ellaway. 2002. "Means of Transport and Ontological Security: Do Cars Provide Psycho-Social Benefits to Their Users?" Transportation Research Part D, 7(2): 119-135.

Institute Development and Urban Planning in the Region of île-de-France. 2015. http://www.iau-idf.fr/en.html.

Kingham, S., J. Dickinson, and S. Copsey. 2001. "Travelling to Work: Will People Move Out of Their Cars." Transport Policy, 8(2): 151-160.

Koslowsky, M., A. N. Kluger, and M. Reich, M. 1995. Commuting Stress: Causes, Effects, and Methods of Coping. Springer Science \& Business Media.

Kuhnimhof, T., B. Chlond, and S. von der Ruhren. 2006. "Users of Transport Modes and Multimodal Travel Behavior." Transport Research Record, 1985: 40-48.

Liu, T., and A. Ceder. 2015. "Analysis of a New Public-Transport-Service Concept: Customized Bus in China." Transport Policy, 39: 63-76.

Martínez, L. M., J. M. Viegas, and T. Eiró. 2014. "Formulating a New Express Minibus Service Design Problem as a Clustering Problem." Transportation Science, 49(1): 85-98.

MoEID. 2015. http://www.prix-carburants.gouv.fr/

Nobis, C., and B. Lenz. 2005. "Gender Differences in Travel Patterns: Role of Employment Status and Household Structure." In Conference Proceedings 35: Research on Women's Issues in Transportation, Vol. 2: Technical Papers, Transportation Research Board of the National Academies, Washington, DC.

Sandow, E. 2011. "On the Road: Social Aspects of Commuting Long Distances to Work." Doctoral dissertation, Umea University, Sweden. 
Shaheen, S. 2001. “Commuter-based Carsharing: Market Niche Potential." Transportation Research Record, 1760: 178-183.

Shaheen, S., D. Sperling, and C. Wagner. 1998. "Carsharing in Europe and North American: Past, Present, and Future." Transportation Quarterly, 52(3):35-52.

Statistics NZ. 2009. “Commuting Patterns in New Zealand: 1996-2006." http:// www.stats.govt.nz/browse_for_stats/Maps_and_geography/Geographic-areas/ commuting-patterns-in-nz-1996-2006.aspx.

Statistics NZ. 2013. 2013 Census. http://www.stats.govt.nz/Census/2013-census.aspx.

Statistics NZ. 2014. "Commuting Patterns in Auckland: Trends from the Census of Population and Dwellings 2006-13." http://www.stats.govt.nz/Census/2013-census/ profile-and-summary-reports/commuting-patterns-auckland.aspx.

Steg, L. 2003. "Can Public Transport Compete with the Private Car?" IATSS Research, 27(2): 27-35.

Stutzer, A., and B. S. Frey. 2008. "Stress that Doesn't Pay: The Commuting Paradox." The Scandinavian Journal of Economics, 110(2): 339-366.

Transit Cooperative Research Program (TCRP). 1999. TCRP Report 55: Guidelines for Enhancing Suburban Mobility Using Public Transportation. TRB, National Research Council, Washington, DC.

Tertoolen, G., D. van Kreveld, and B. Verstraten. 1998. "Pyschological Resistance against Attempts to Reduce Private Car Use." Transportation Research Part A, 32(3): 171181.

Xu, M., S. Grant-Muller, H. J. Huang, and Z. Gao. 2015. "Transport Management Measures in the Post-Olympic Games Period: Supporting Sustainable Urban Mobility for Beijing?" International Journal of Sustainable Development \& World Ecology, 22(1): 50-63.

Ye, X., R. M. Pendyala, and G. Gottardi. 2007. "An Exploration of the Relationship between Mode Choice and Complexity of Trip Chaining Patterns." Transportation Research Part B, 41(1): 96-113.

\section{About the Authors}

TAO LIU (tliu773@aucklanduni.ac.nz) is currently a Ph.D. student in the Department of Civil and Environmental Engineering at The University of Auckland. He received a B.Eng. in Traffic Engineering and an M.Eng. in Systems Engineering from Beijing Jiaotong University in 2011 and 2013, respectively. He specializes in transportation systems analysis, public transportation and intelligent transportation systems.

Avishal (Avi) Ceder (a.ceder@auckland.ac.nz) is a Professor-Chair in Transportation in the Department of Civil and Environmental Engineering at The University of Auckland and is the Founder and was the Director, until 2014, of the Transportation Research Centre (TRC). He has served as Head of the Transportation Engineering and 
Geo-Information Department at the Technion, Chief Scientist at the Israel Ministry of Transport from 1994 to 1997, and the Israel delegate to the Transport Program of the European Community. He is a member of various international symposia and workshops. In 2007, he published Public Transit Planning and Operation: Theory, Modelling and Practice (Elsevier), which was translated to Chinese by Tsinghua Press in 2010; the second edition, Public Transit Planning and Operation: Modelling, Practice and Behavior was published in July 2015 by CRC Press.

Romain Bologna was, in 2015, with The University of Auckland, New Zealand. Currently, he is with the Urban Engineering School of EIVP in Paris.

Benjamin Cabantous was, in 2015, with The University of Auckland, New Zealand. Currently, he is with the Urban Engineering School of EIVP in Paris. 